Synergistic Catalysis: Pd(II) Catalyzed Oxidation of 1,4-Dihydroquinones in the Pd(II) Catalyzed

\title{
1,4-Oxidation of Cyclic-1,3-Dienes
}

Bin Zheng, Michael A. Schmidt and Martin D. Eastgate*

Early Phase Chemical Development, Bristol-Myers Squibb, 1 Squibb Drive, New Brunswick, NJ, 08903, USA

Martin.Eastgate@bms.com

Supplementary Information

Kinetic Reaction Profile with Variable Acid Concentrations

NMR Spectra

${ }^{1} \mathrm{H}$ NMR Compound $3 \mathrm{a}$

${ }^{1}$ H NMR Compound BQ

${ }^{1} \mathrm{H}$ NMR Compound $\mathbf{5 a}$ S4

${ }^{1} \mathrm{H}$ NMR Compound $\mathbf{5 b}$

${ }^{1} \mathrm{H}$ NMR Compound $5 \mathrm{c}$

S5

${ }^{1} \mathrm{H}$ NMR Compound 8

${ }^{1} \mathrm{H}$ NMR Compound 11a

${ }^{13}$ C NMR Compound 11 a

${ }^{1} \mathrm{H}$ NMR Compound 11b

${ }^{13}$ C NMR Compound 11 b

${ }^{1} \mathrm{H}$ NMR Compound 11c

${ }^{13} \mathrm{C}$ NMR Compound $11 \mathrm{c}$ $\mathrm{S} 11$

${ }^{1} \mathrm{H}$ NMR Compound $\mathbf{1 1 d}$ $\mathrm{S} 12$

${ }^{13}$ C NMR Compound $11 d$ $\mathrm{S} 13$

${ }^{1} \mathrm{H}$ NMR Compound 11e S14

${ }^{13}$ C NMR Compound 11e $\mathrm{S} 15$

${ }^{1} \mathrm{H}$ NMR Compound $\mathbf{1 1 f}$

${ }^{13} \mathrm{C}$ NMR Compound 11f S16

${ }^{1} \mathrm{H}$ NMR Compound $\mathbf{1 1 g}$ $\mathrm{S} 17$

${ }^{13} \mathrm{C}$ NMR Compound $\mathbf{1 1 g}$ S18

${ }^{1} \mathrm{H}$ NMR Spectra for d $r$. Determination of the Trans isomer in Table 4 (Compounds 11a-c)S20 HPLC Spectra for d.r. Determination of the Trans isomer in Table 4 (Compounds 11d-g) S21 


\section{Kinetic Reaction Profiles with Variable Acid Concentrations:}

Reaction was performed understand conditions, with varying acid concentrations. Reactions were monitored by HPLC and the conversion monitored by quantitative HPLC.

\section{Graph S1}

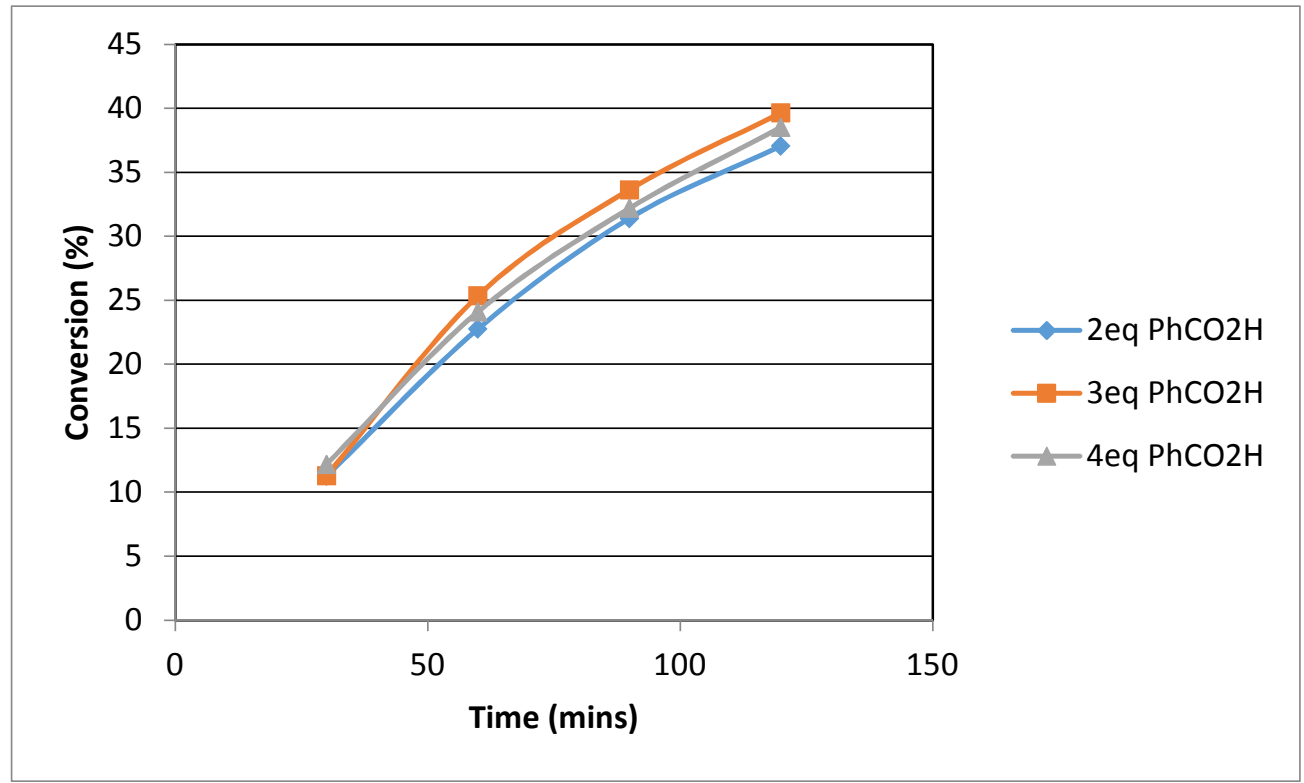




\section{NMR Spectra}

$3 a$

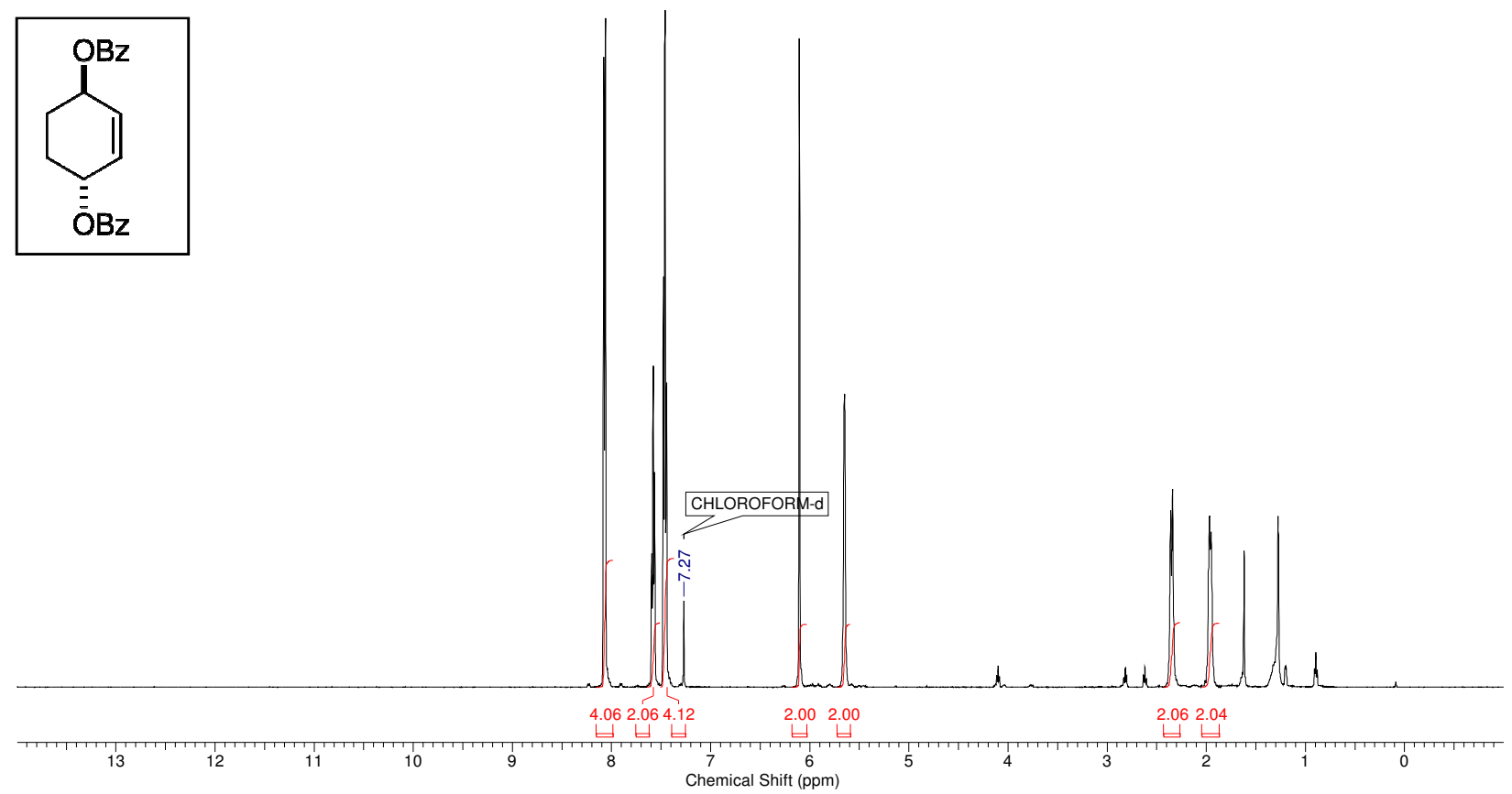

BQ

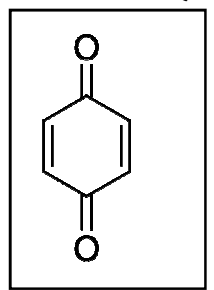

CHLOROFORM-d

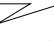

疍

.00

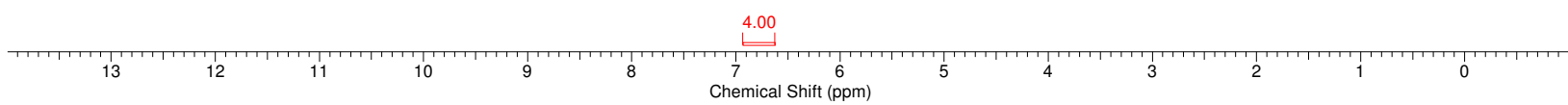


$5 a$
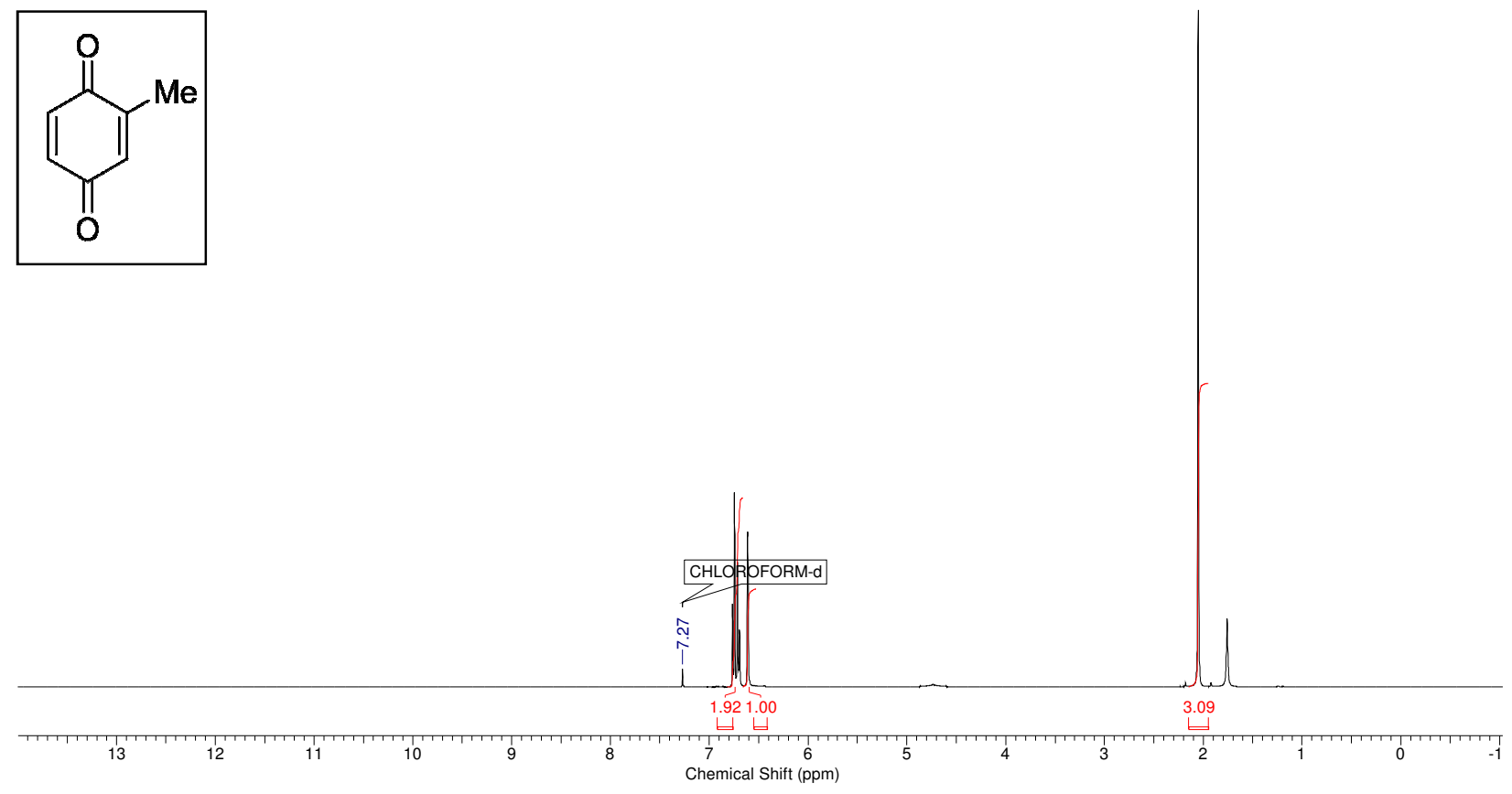

$5 b$
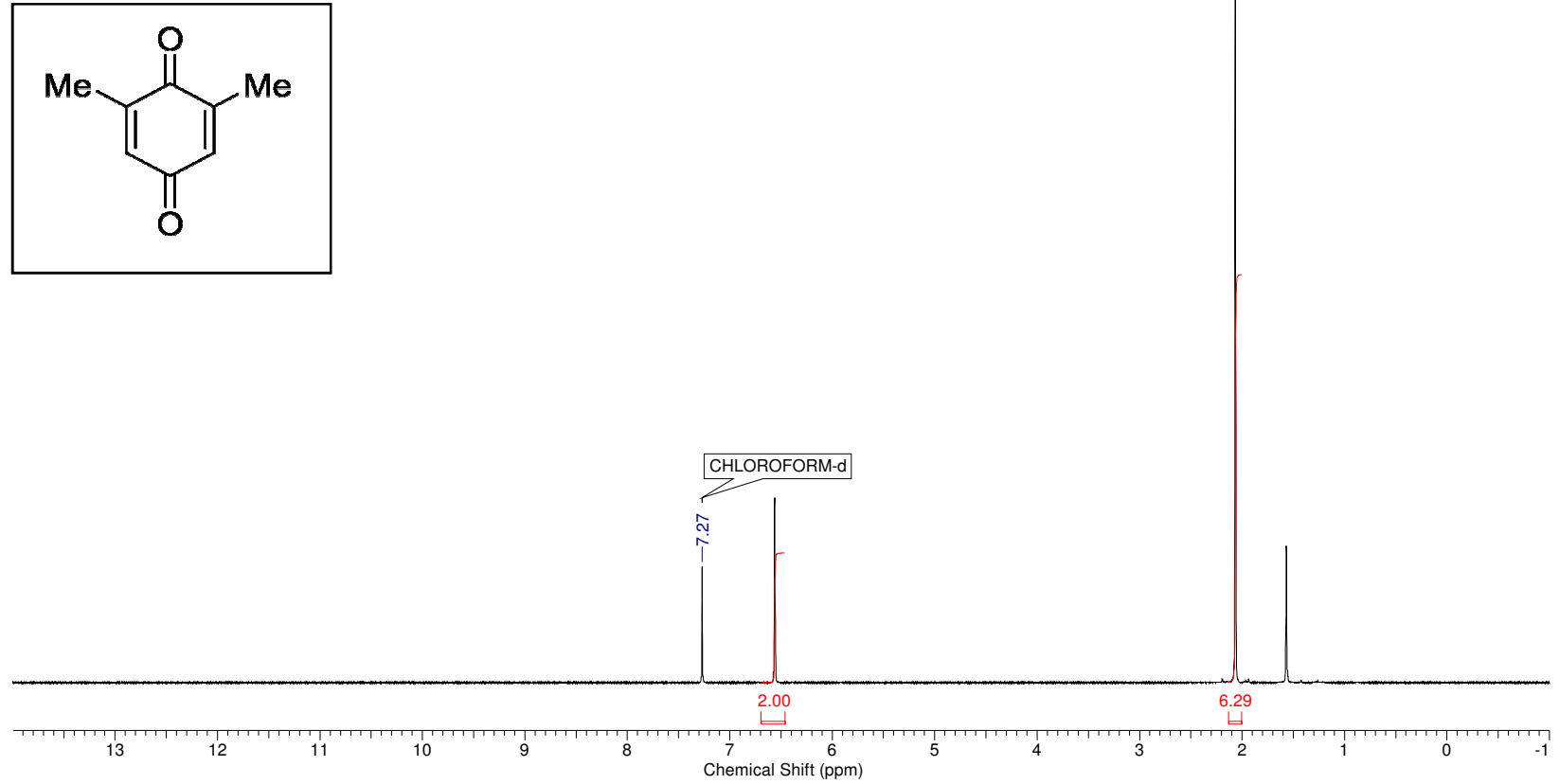


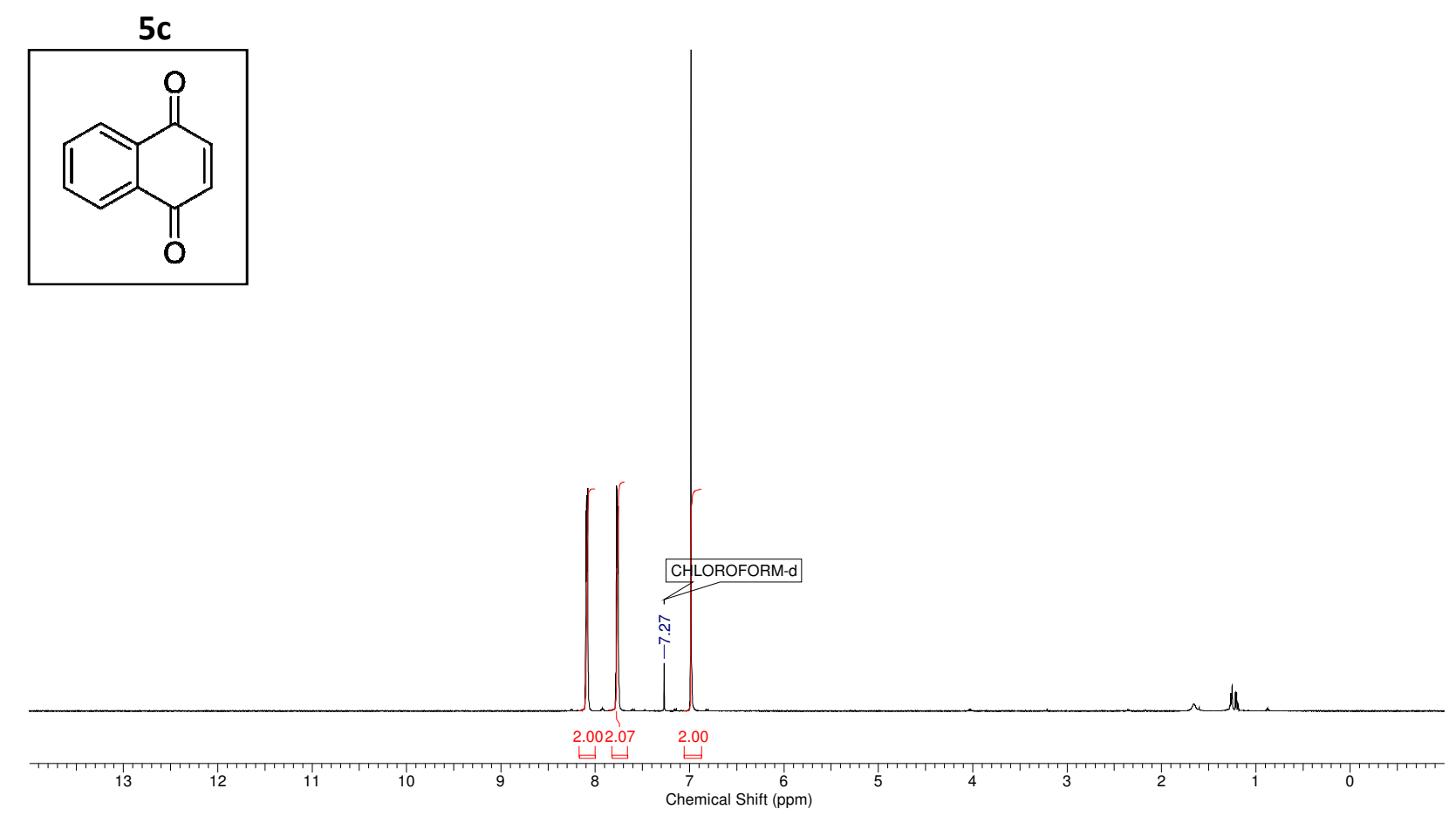

8
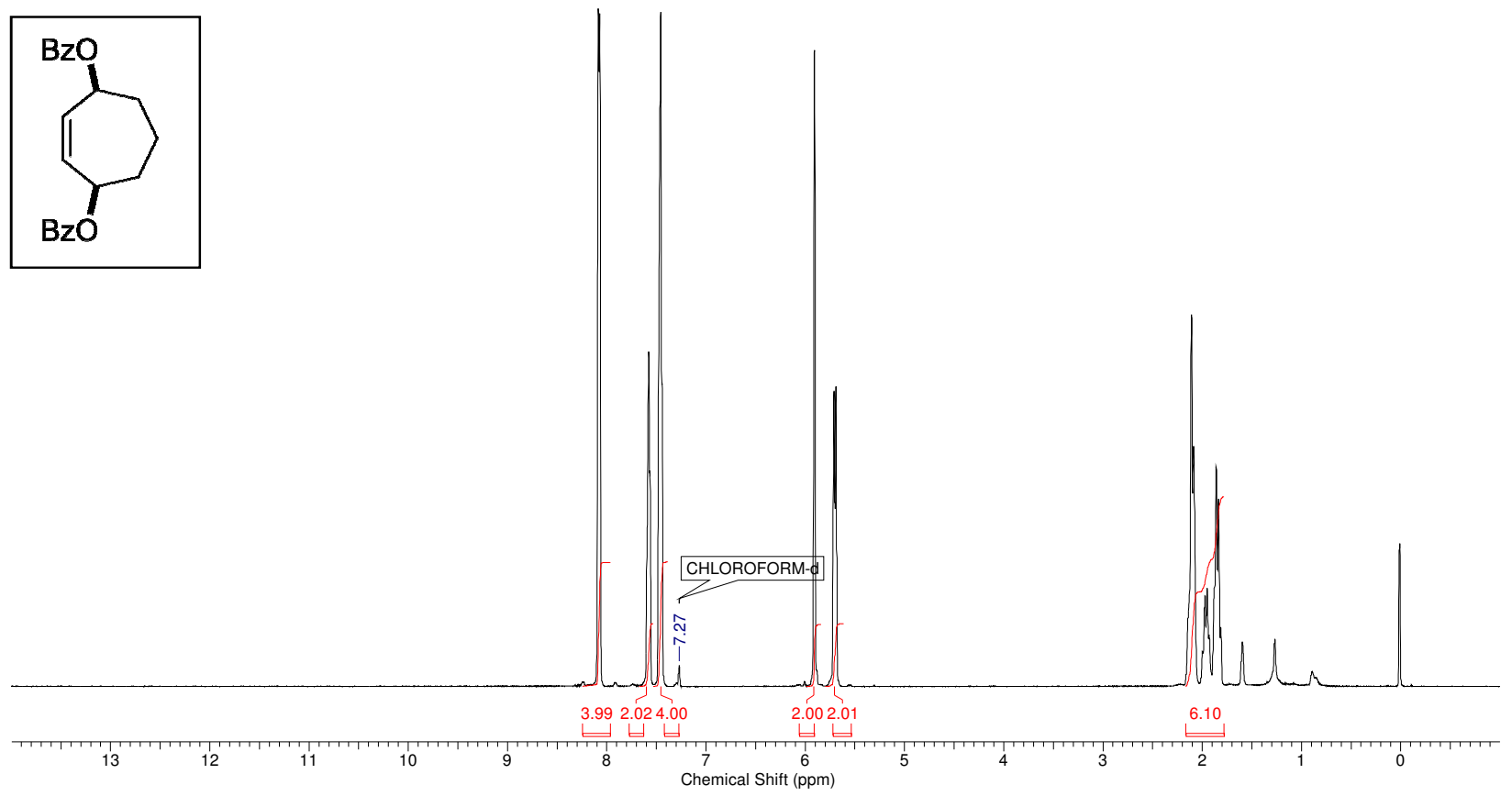
$11 a$
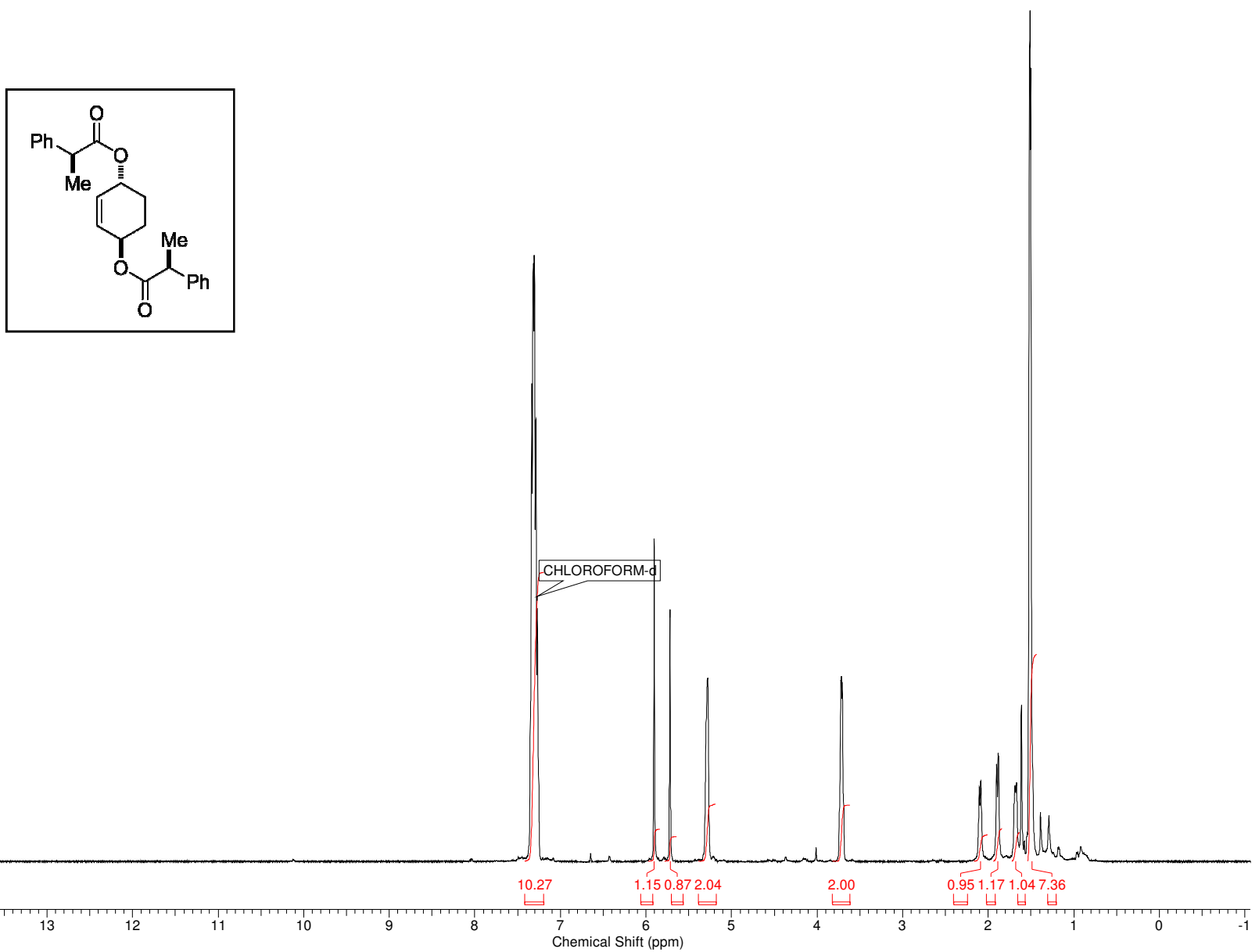
$11 a$

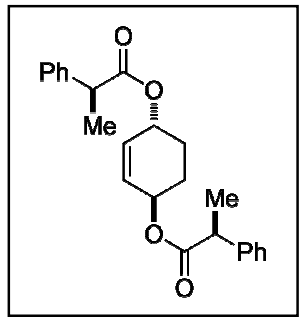

CHLOROFORM-d
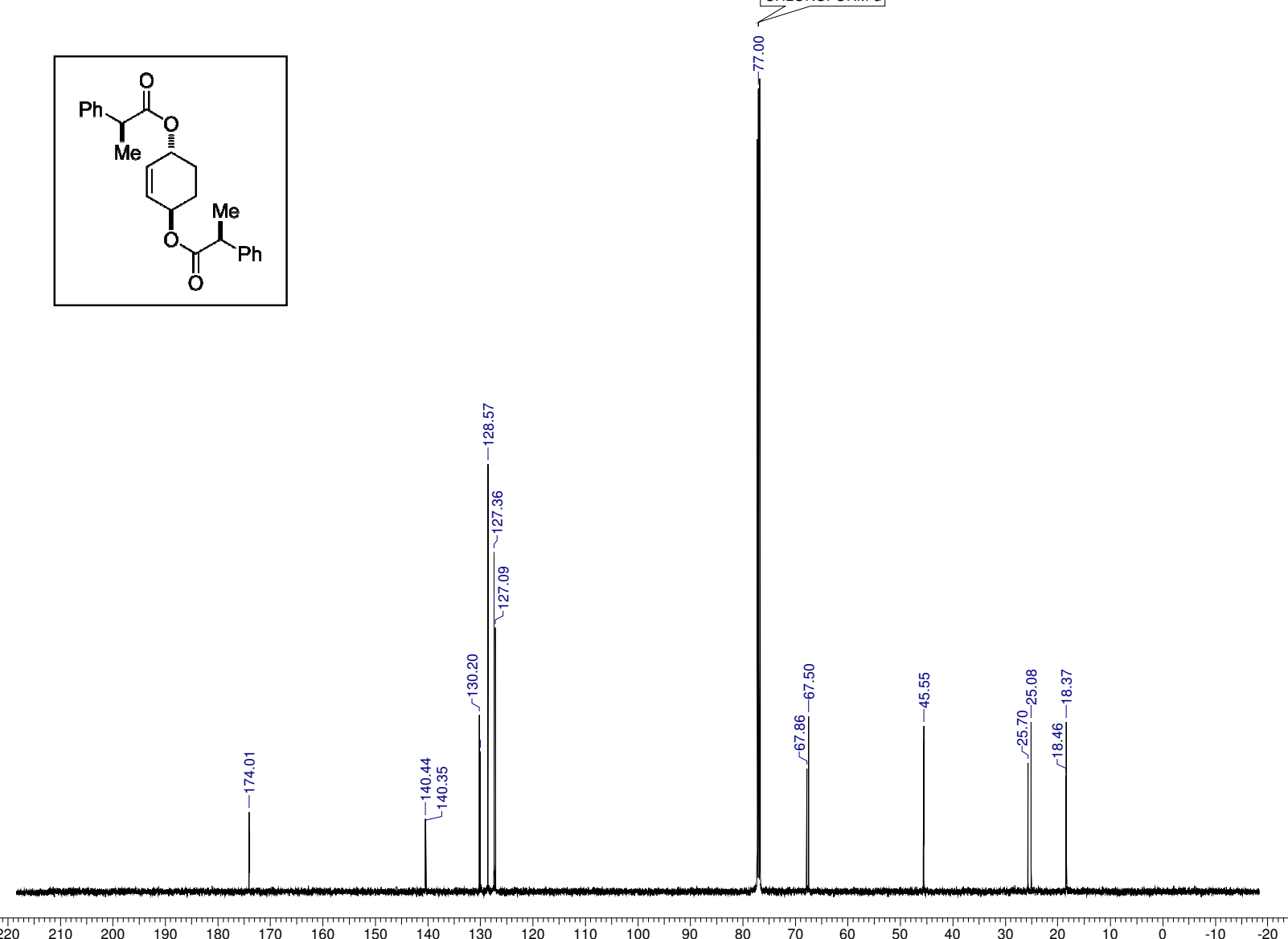
11b
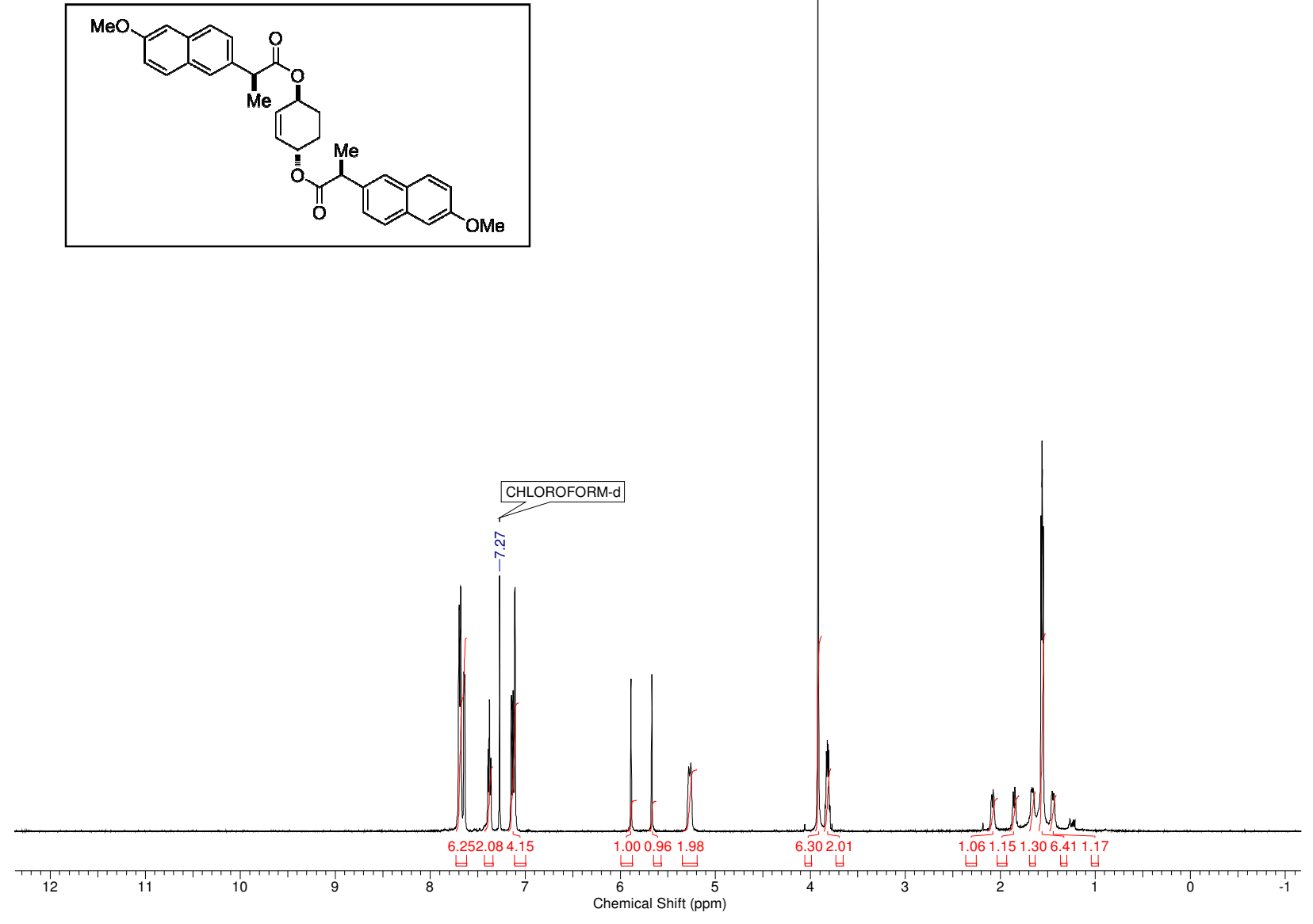
S9

11b

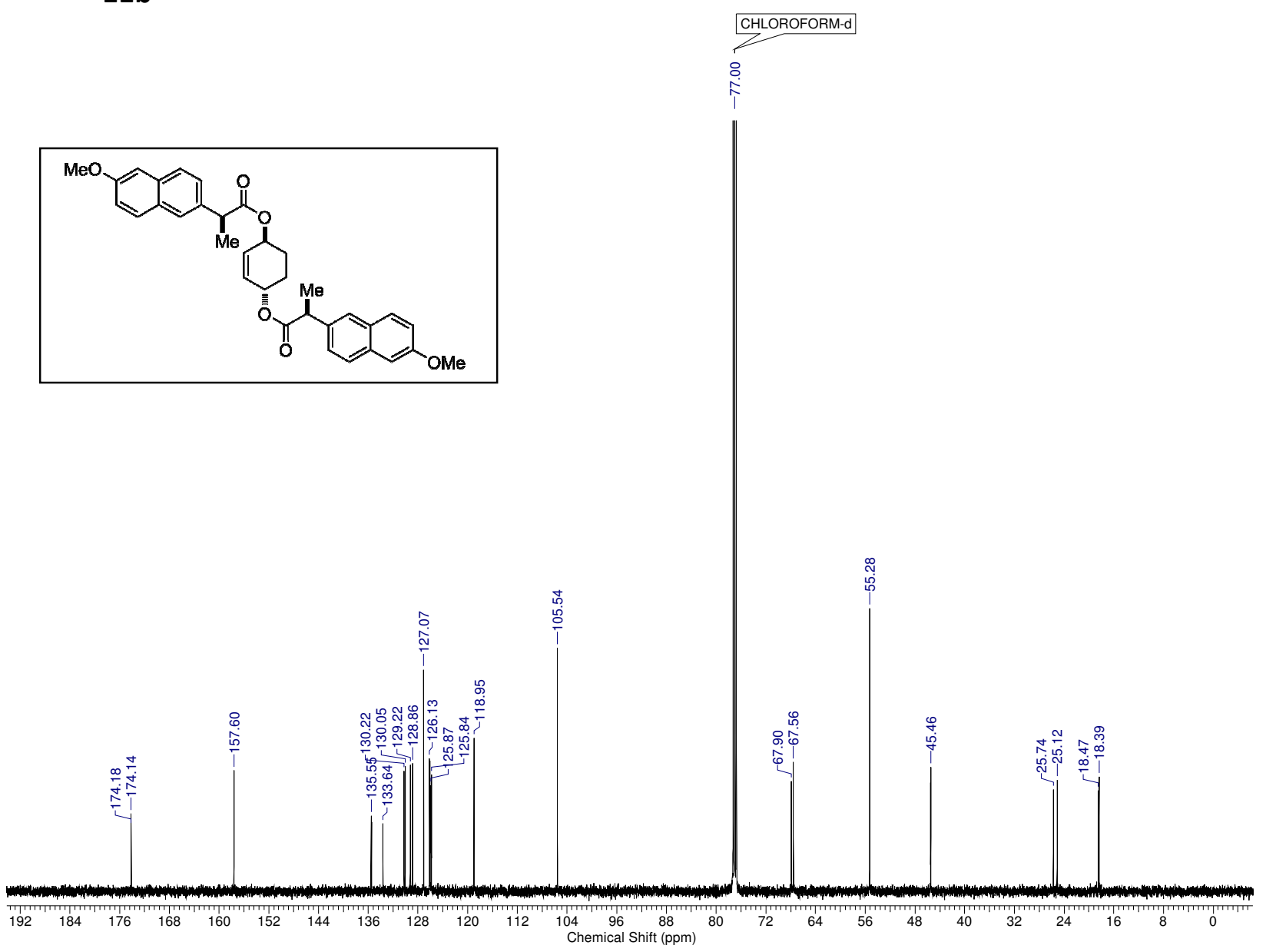


11c
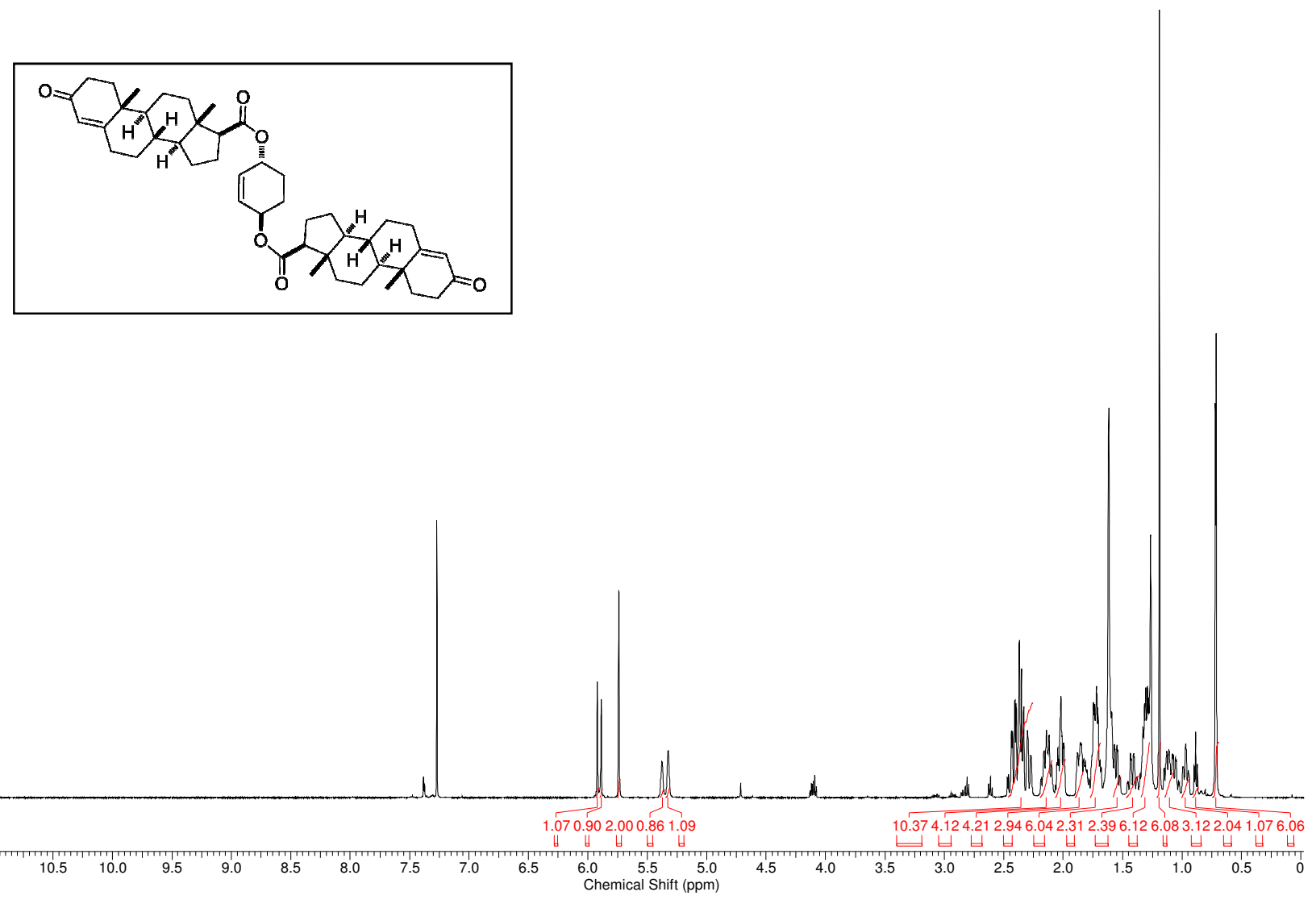
11c

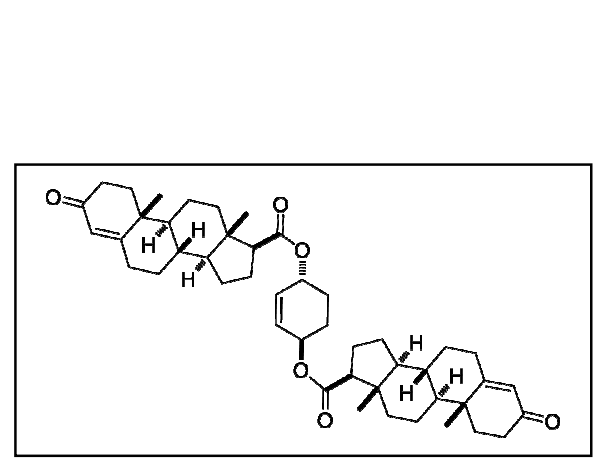

CHLOROFORM-d

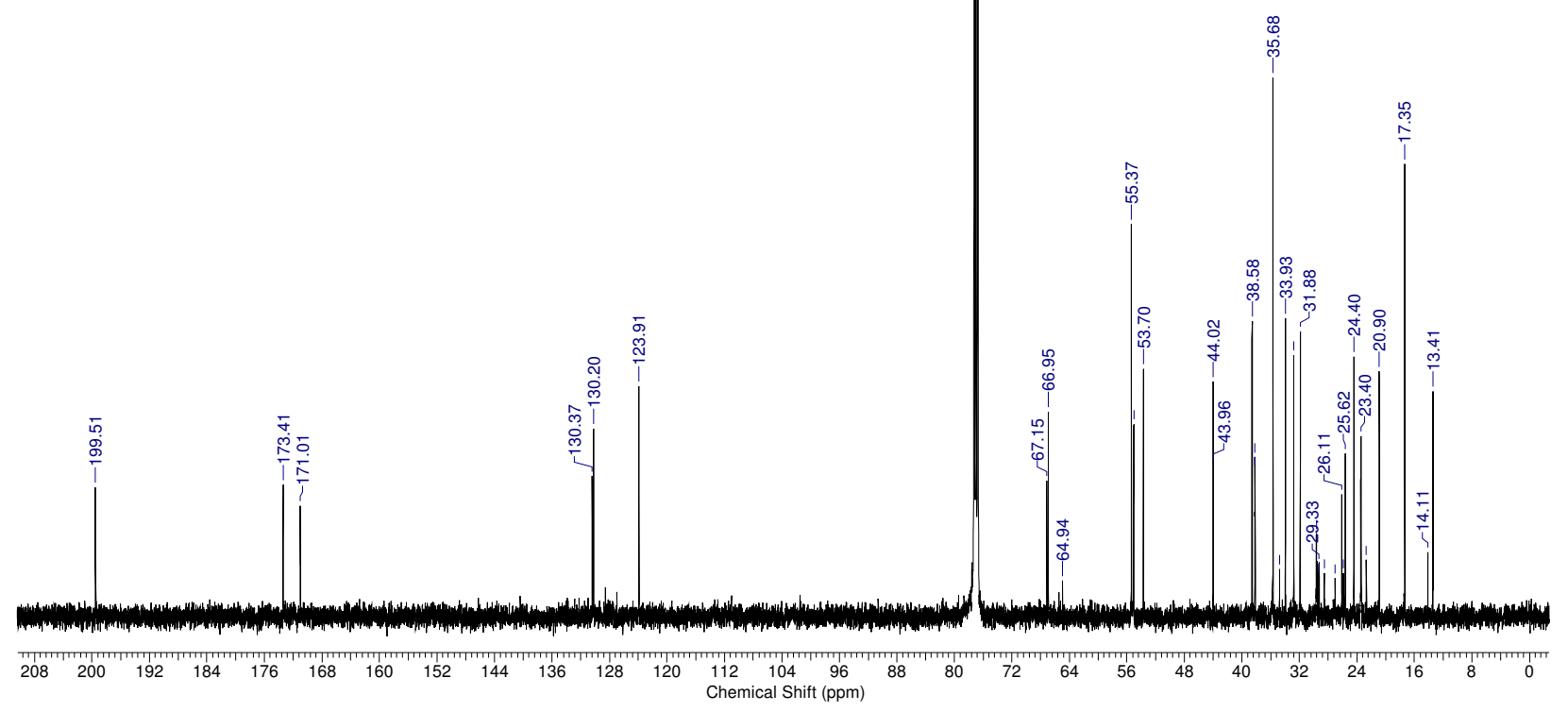


11d
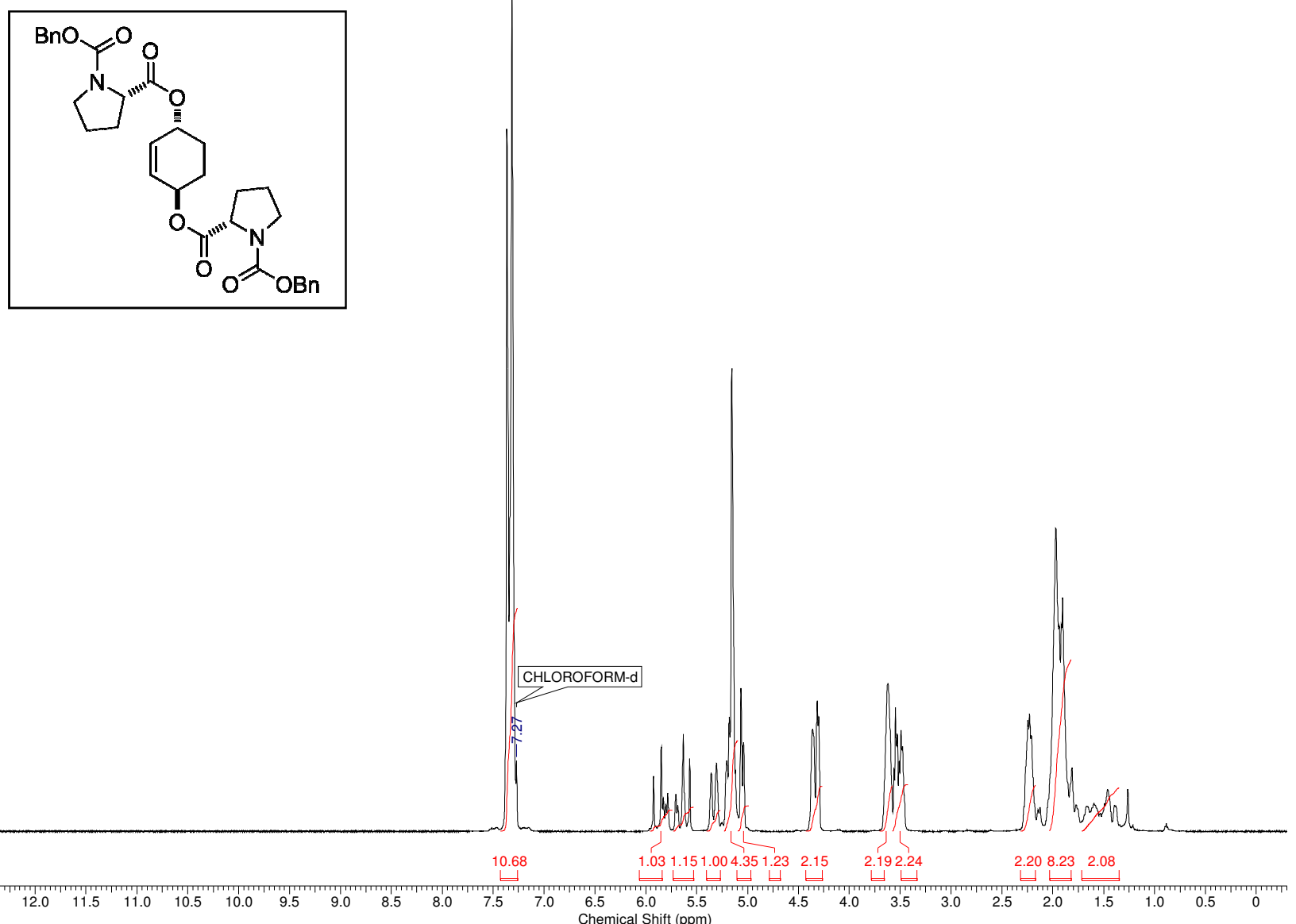
11d

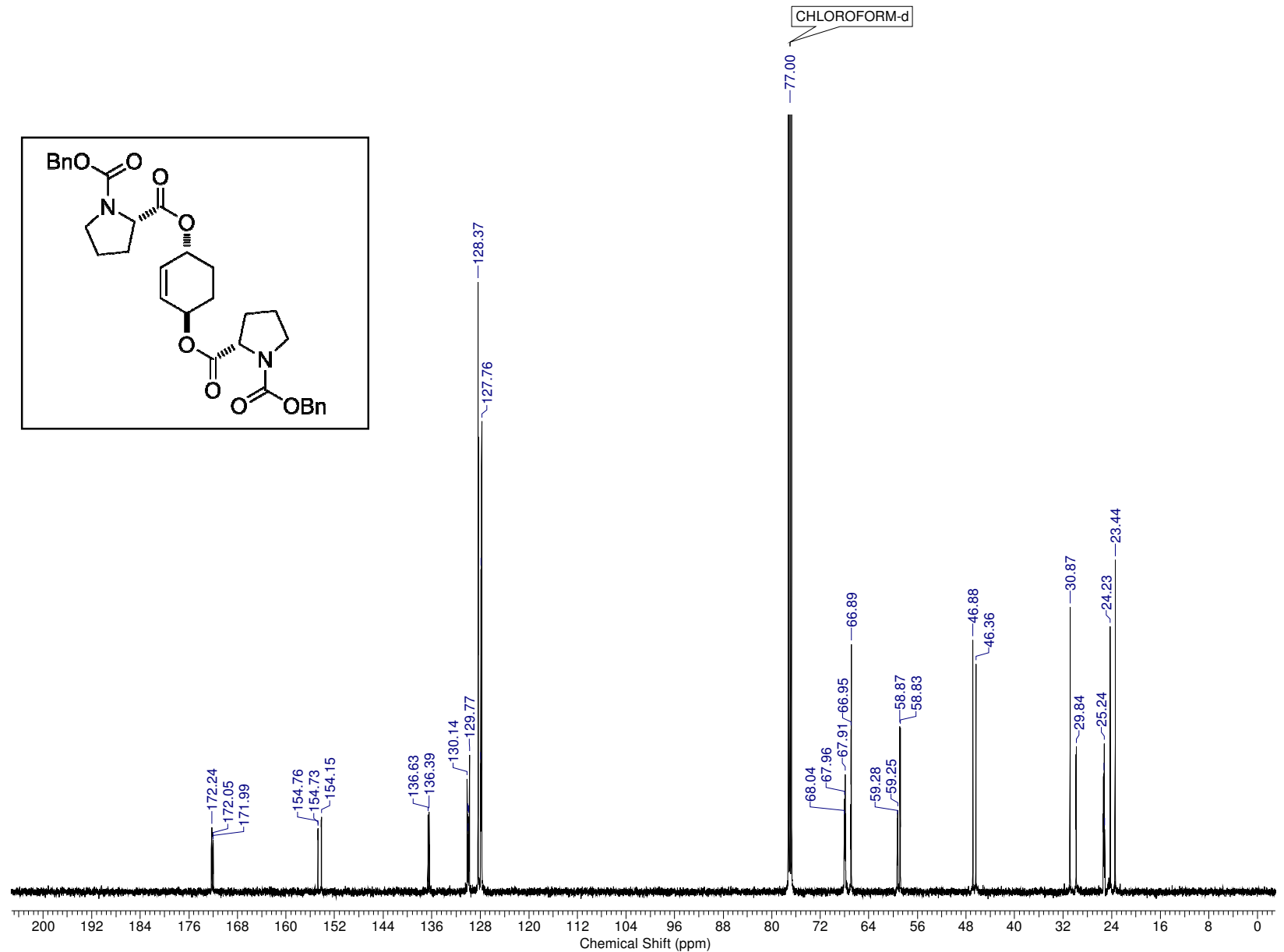

CHLOROFORM-d 
$11 e$
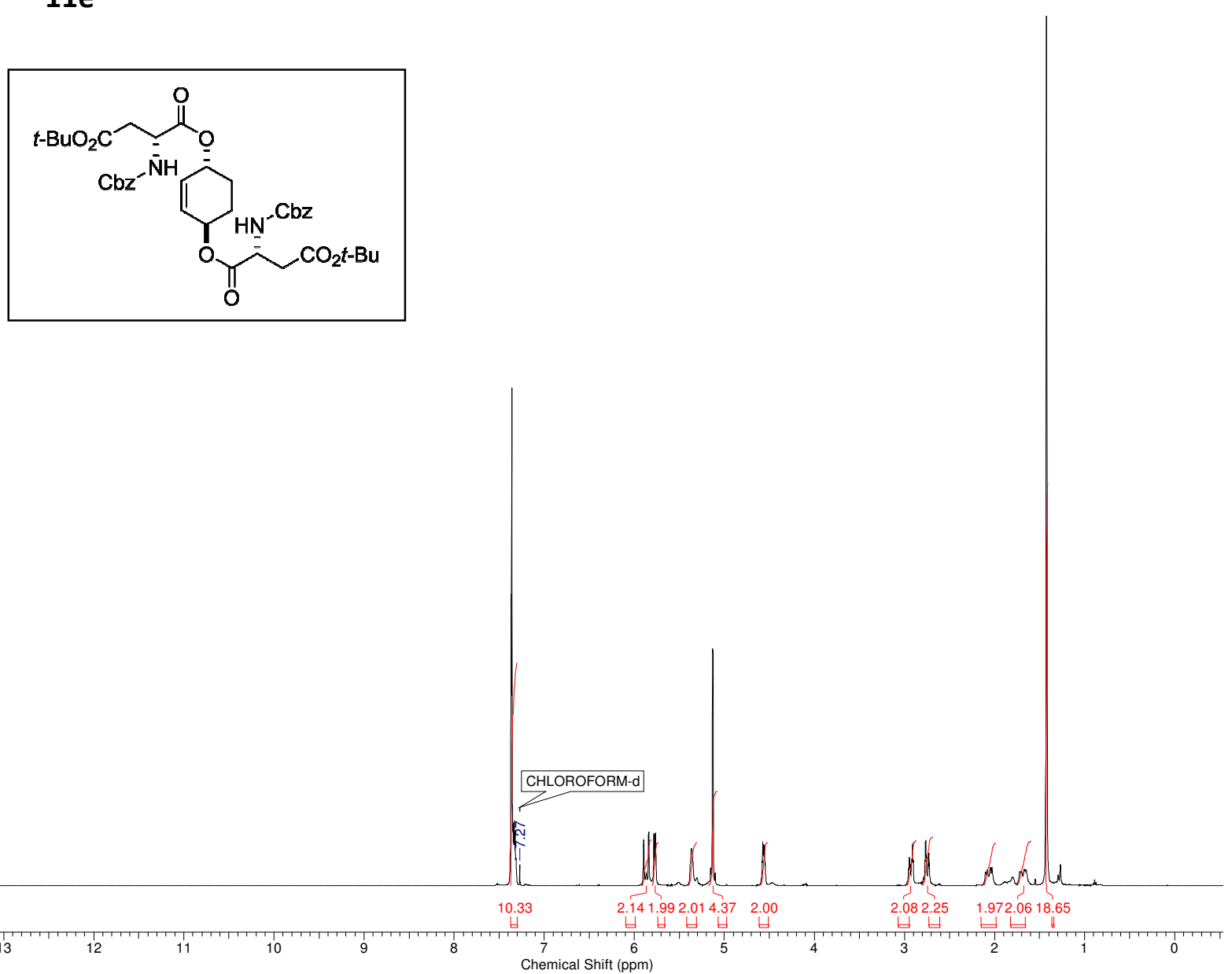


\section{$11 e$}

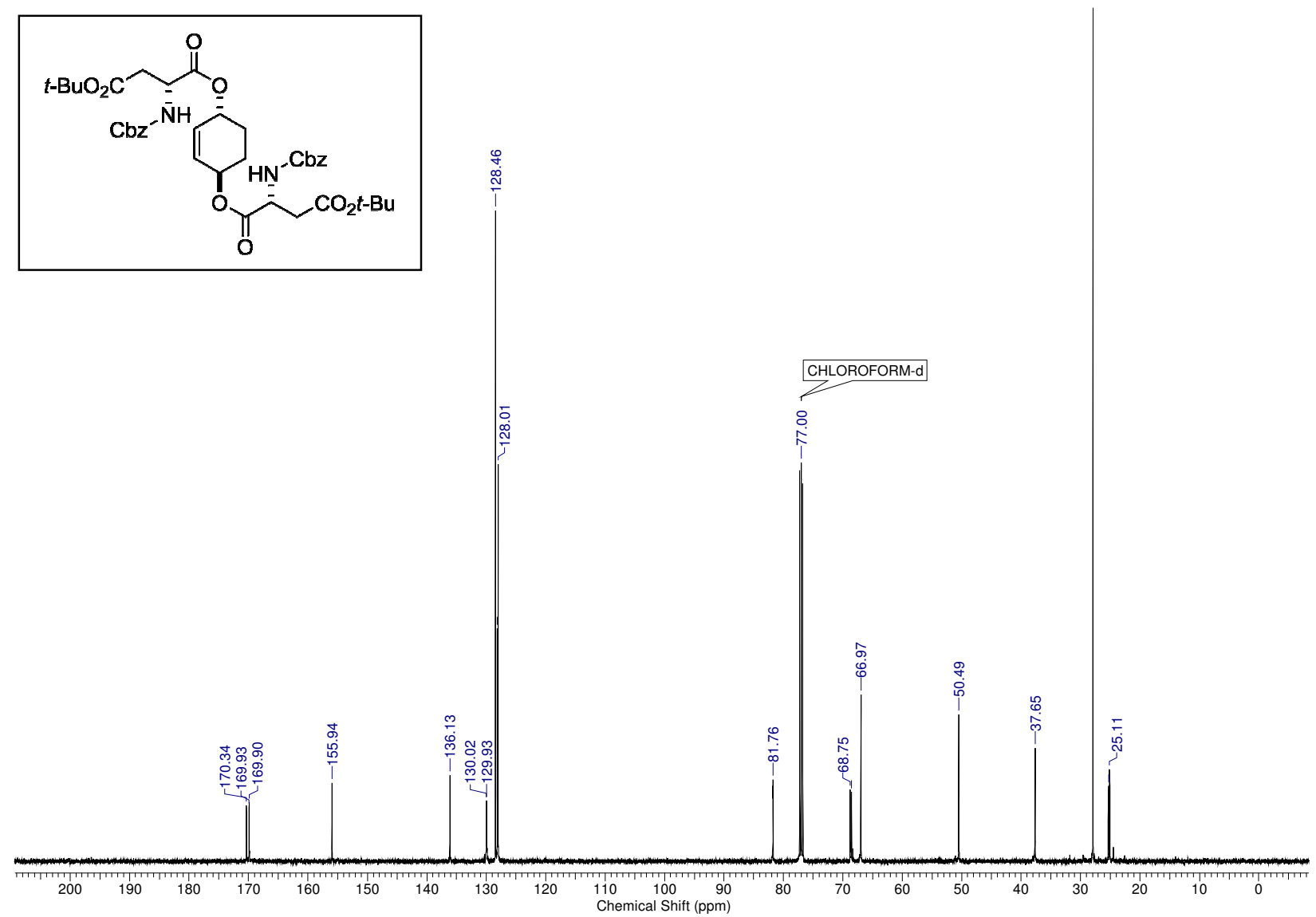




\section{$11 f$}
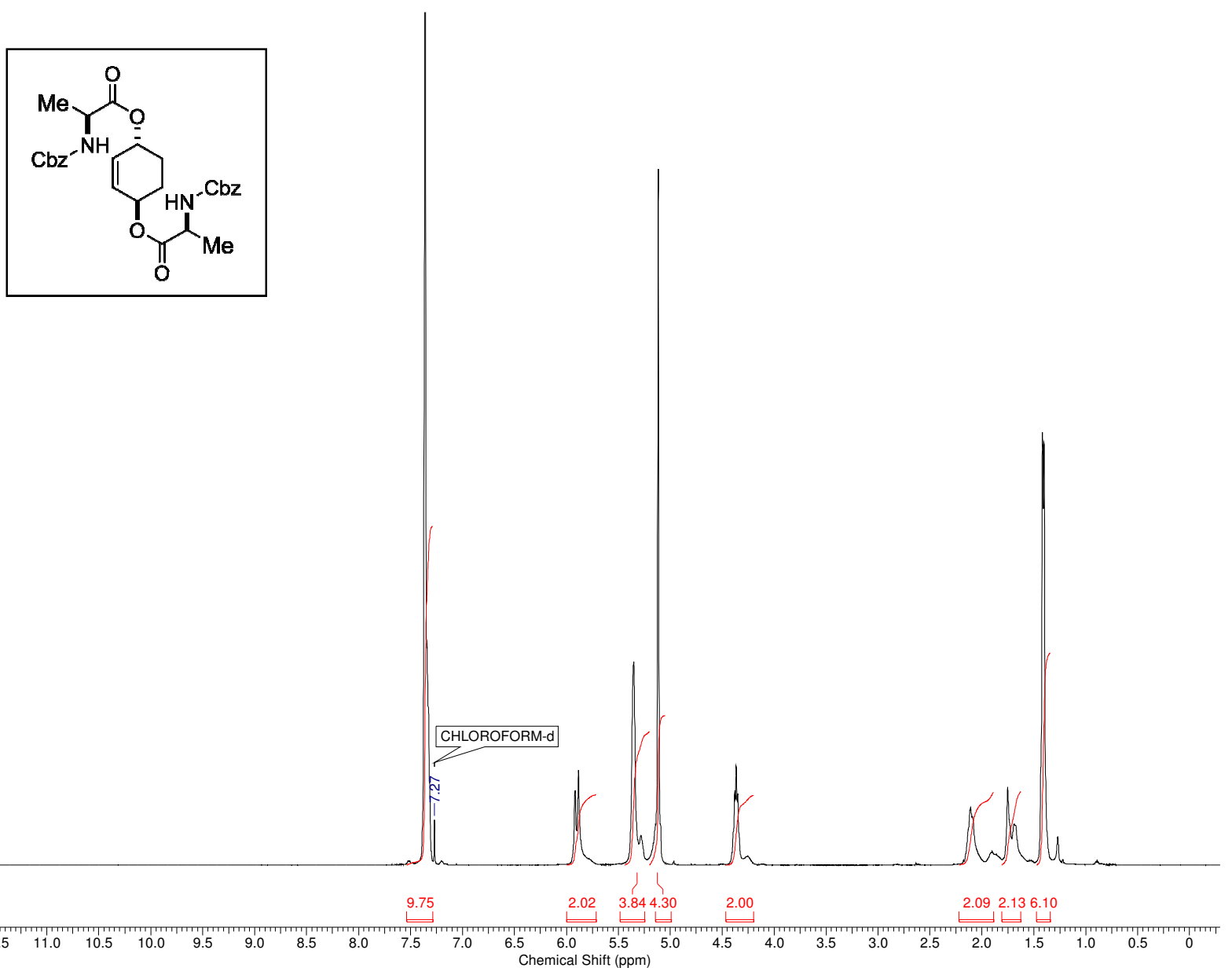


\section{$11 f$}

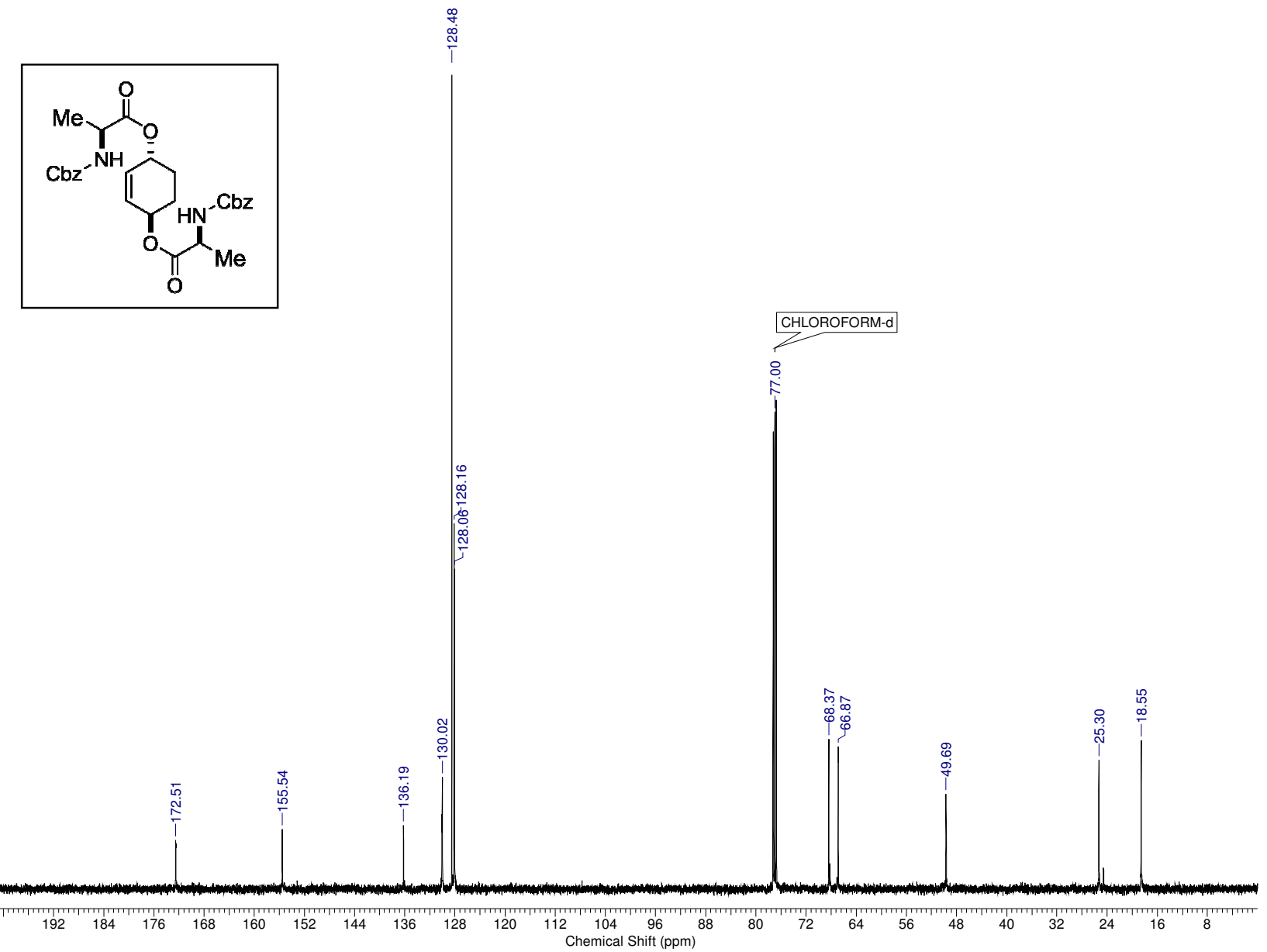


11g
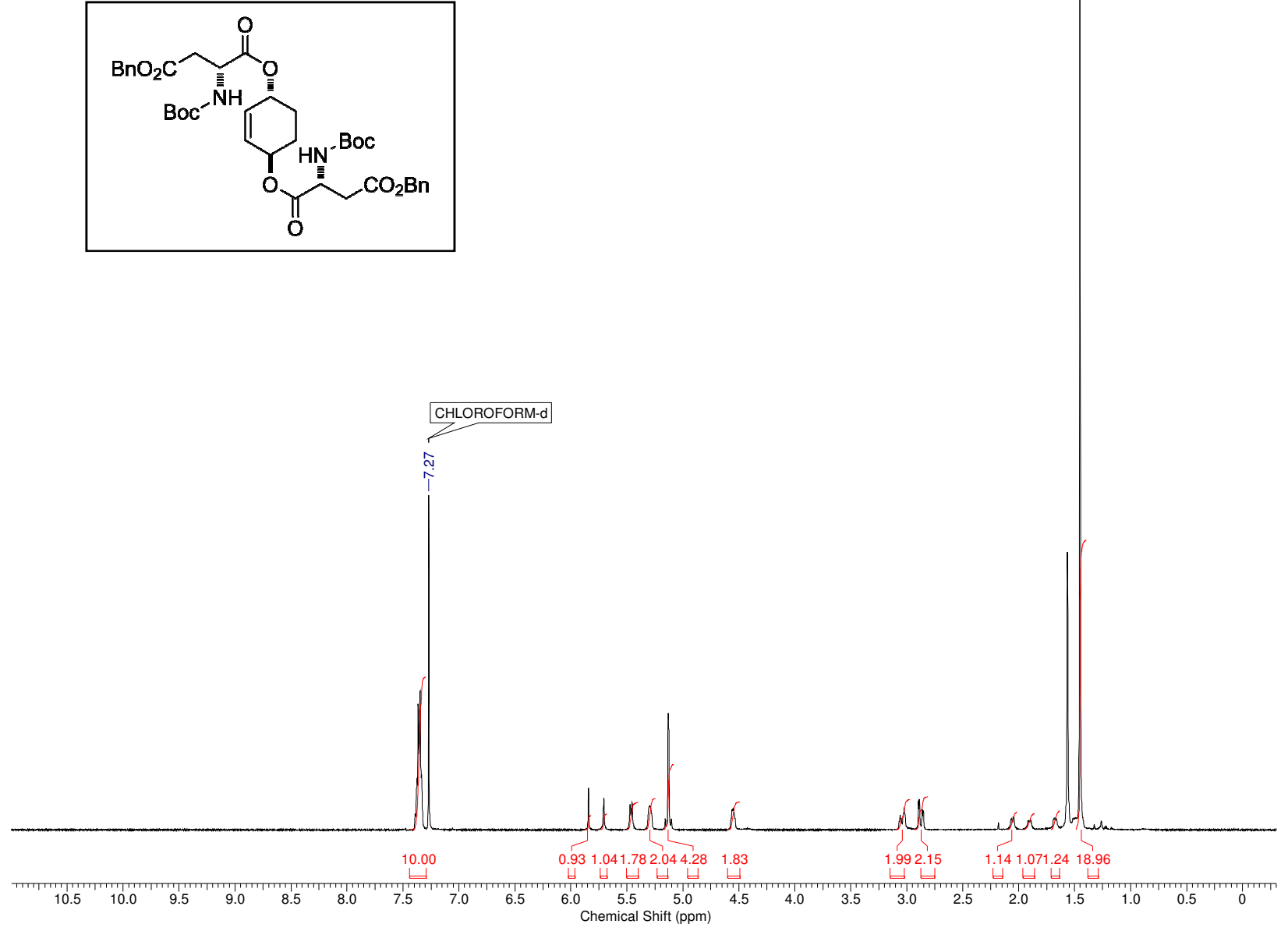
$11 g$
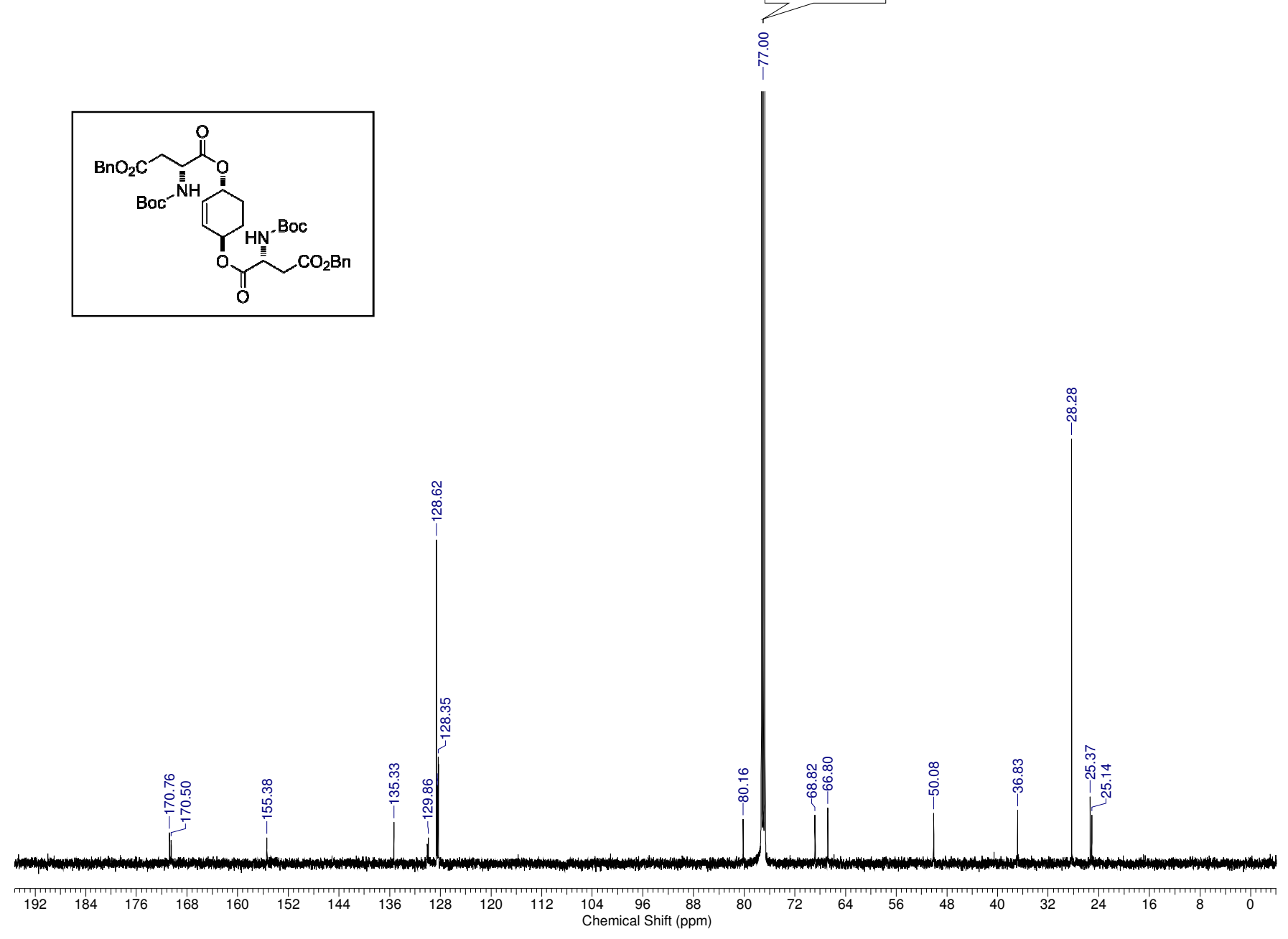


\section{${ }^{1} \mathrm{H}$ NMR traces for determining the d.r. of the Trans isomers in Table 4}

The d.r. of compounds 11a-11c were determined by NMR of partially purified reactions mixtures. This was done in order to removed impurities that obscured the diagnostic resonances.

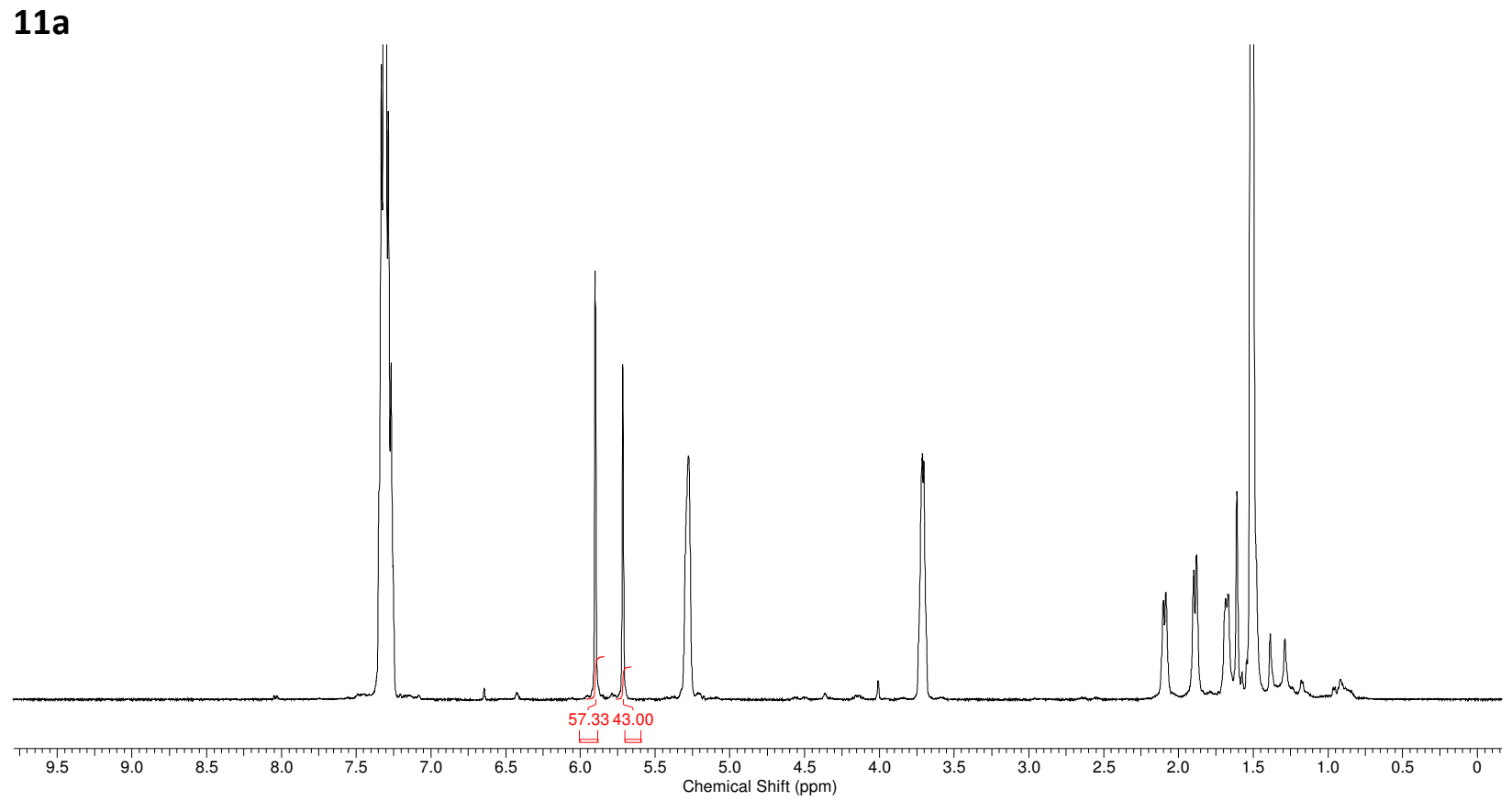

$11 b$

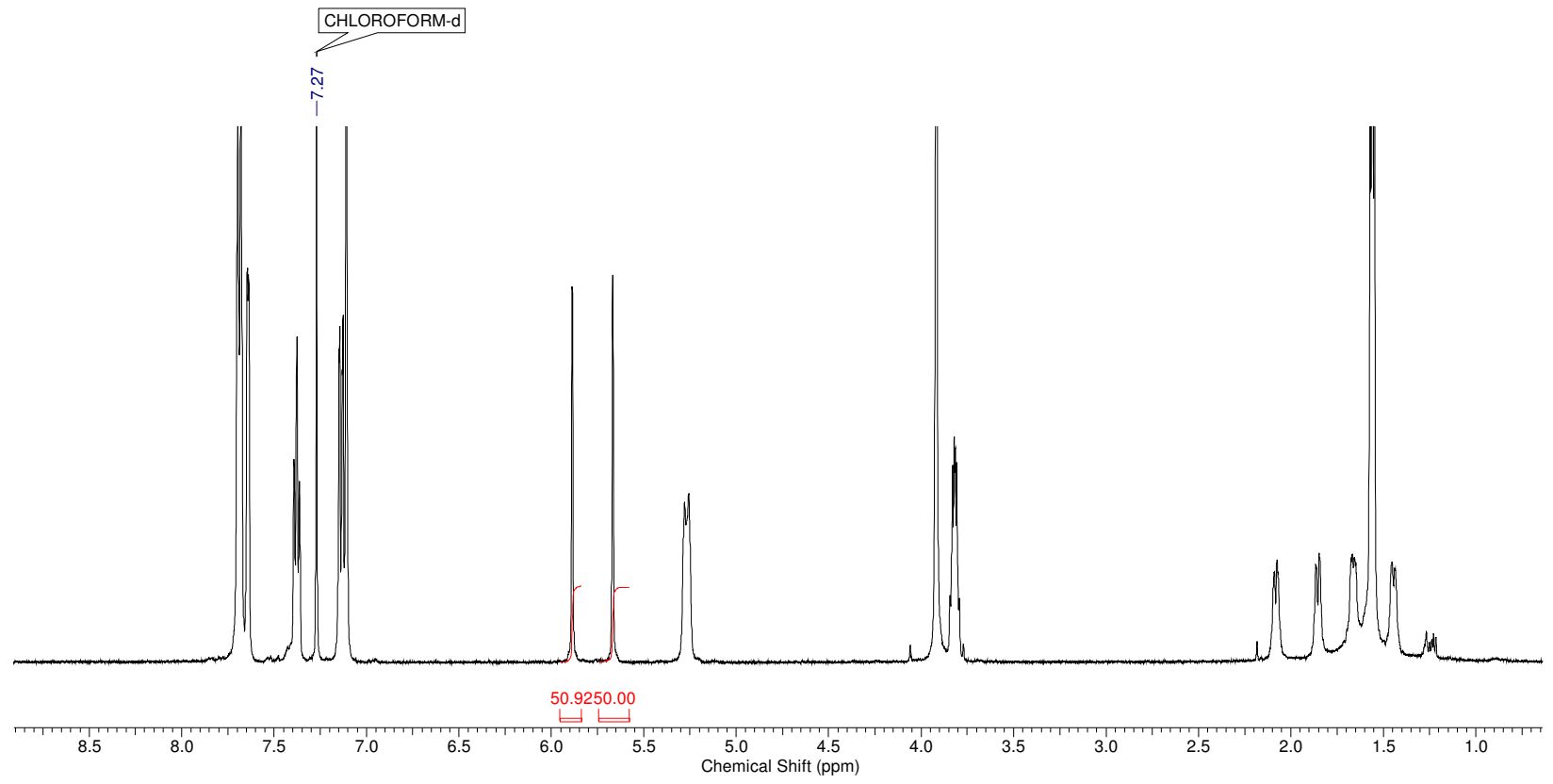




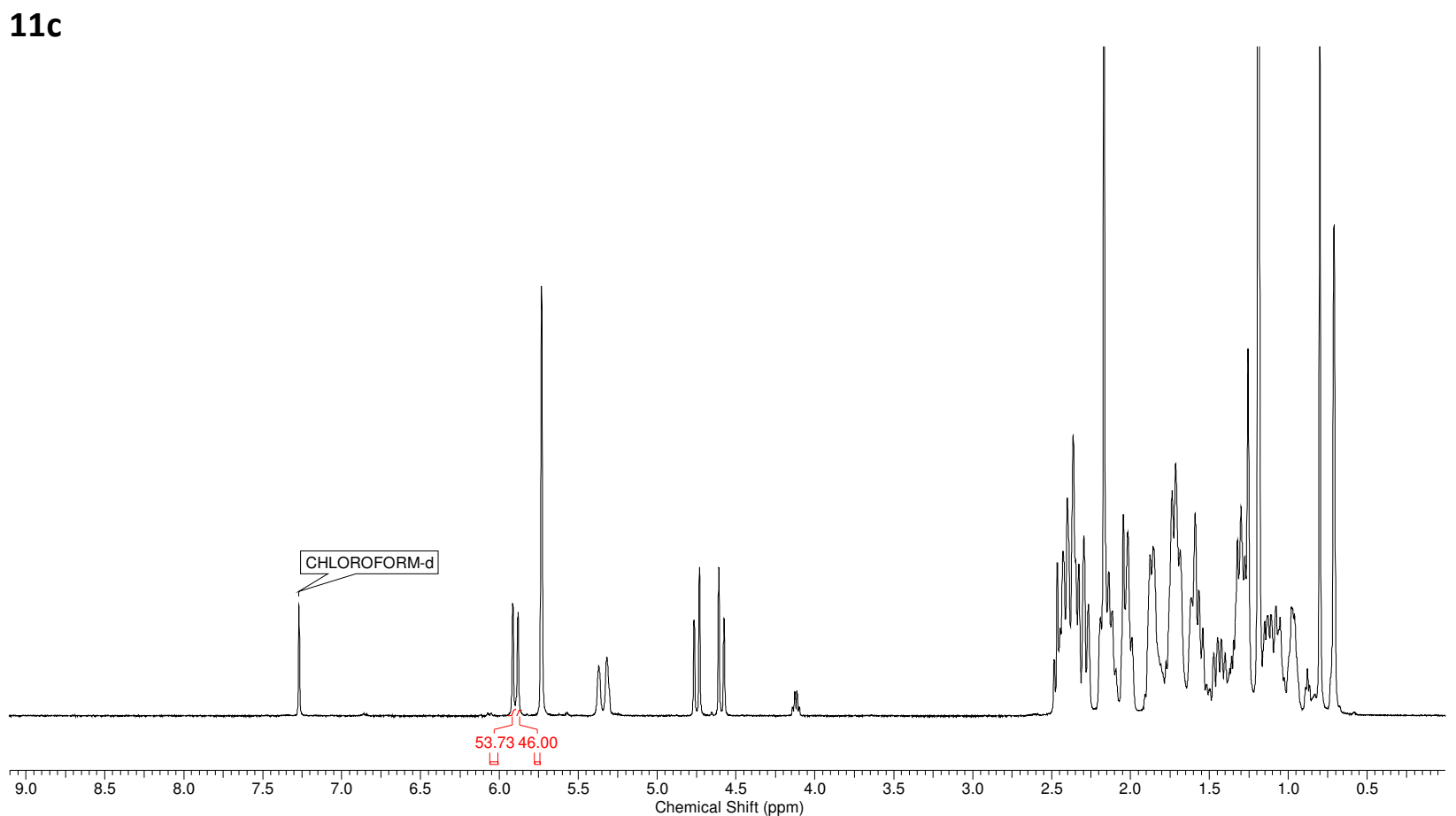

HPLC traces for determining the d.r. of the Trans isomers in Table 4

The d.r. of compounds $11 \mathrm{~d}-11 \mathrm{~g}$ were determined by HPLC of the crude reaction mixture as described in the text. For column and method information, please see the text.

\section{1d}

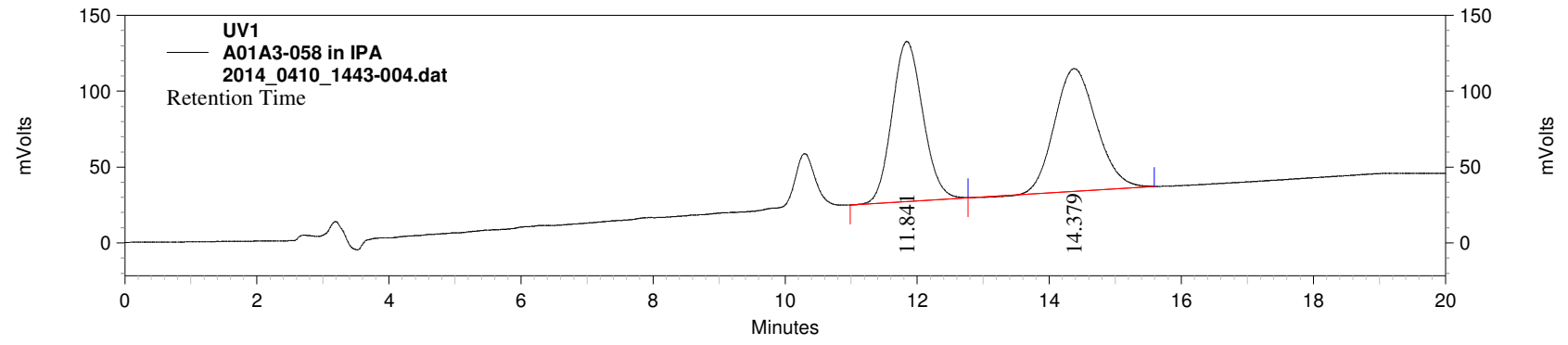

\begin{tabular}{cccc}
$\begin{array}{c}\text { UV1 Results } \\
\text { Pk \# }\end{array}$ & RT $(\min )$ & Area & Area Percent \\
\hline 1 & 11.84 & 3419004 & 49.04 \\
2 & 14.38 & 3553160 & 50.96
\end{tabular}




\begin{tabular}{|l|l|l|l|}
\hline Totals & & 6972164 & 100.00 \\
\hline
\end{tabular}

\section{$11 e$}

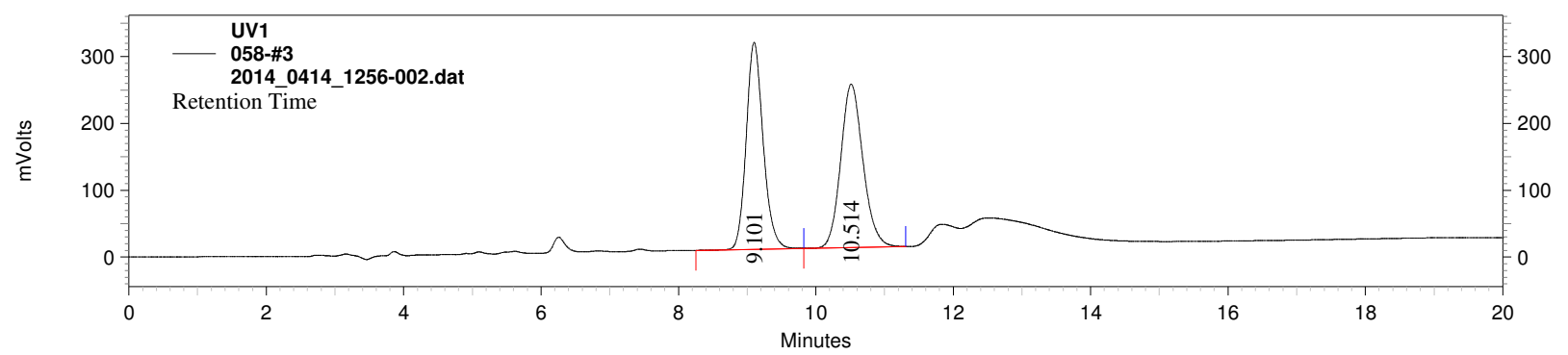

UV1 Results

\begin{tabular}{cccc} 
Pk\# & RT $(\min )$ & Area & Area Percent \\
\hline 1 & 9.10 & 5356218 & 49.63 \\
2 & 10.51 & 5439040 & 50.37
\end{tabular}

\begin{tabular}{|l|l|l|l|}
\hline Totals & & 10795258 & 100.00 \\
\hline
\end{tabular}

\section{$11 f$}

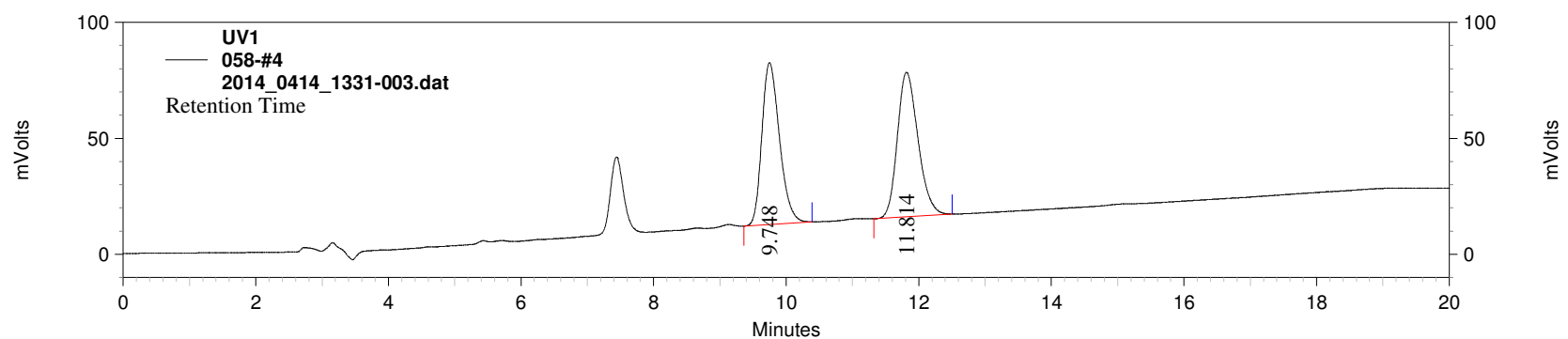

\begin{tabular}{ccccc}
$\begin{array}{c}\text { UV1 Results } \\
\text { Pk \# }\end{array}$ & RT (min) & Area & Area Percent \\
\hline 1 & 9.75 & 1286186 & 48.86 \\
2 & 11.81 & 1346356 & 51.14 \\
\hline \multicolumn{2}{l}{} & 2632542 & 100.00 \\
\hline
\end{tabular}


11g

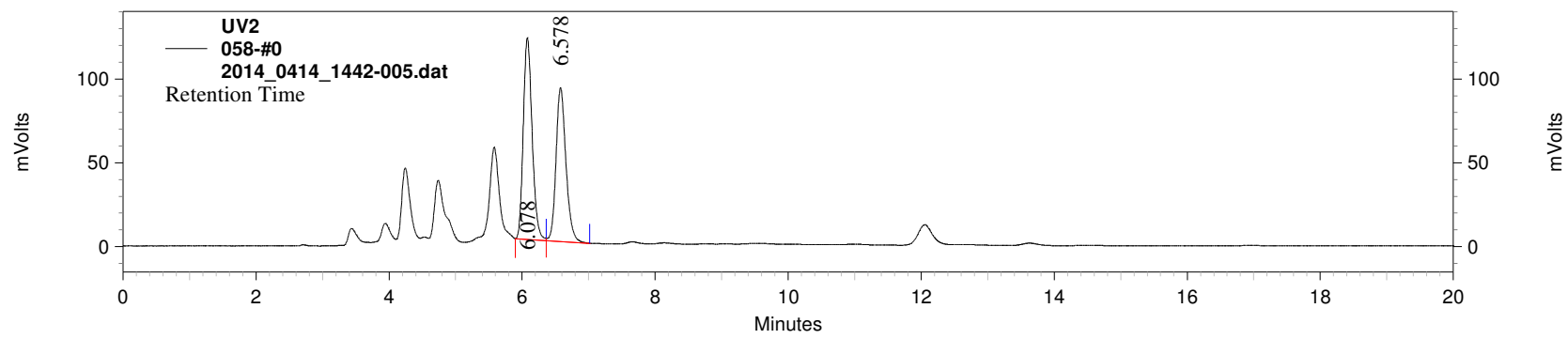

\begin{tabular}{cccc}
$\begin{array}{c}\text { UV2 Results } \\
\text { Pk \# }\end{array}$ & RT $(\min )$ & Area & Area Percent \\
\hline 1 & 6.08 & 1100762 & 53.45 \\
2 & 6.58 & 959341 & 46.55 \\
\multicolumn{1}{l|}{} & 2060103 & 100.00 \\
\hline Totals & & & \\
& &
\end{tabular}

